\title{
Kearns-Sayre syndrome is genetically and phenotypically heterogeneous
}

\author{
Josef Finsterer, ${ }^{1}$ Sinda Zarrouk-Mahjoub ${ }^{2}$ \\ ${ }^{1}$ Krankenanstalt Rudolfstiftung, Messerli Institute, Veterinary University of Vienna, Vienna, Austria; ${ }^{2}$ University of Tunis \\ El Manar and Genomics Platform, Pasteur Institute of Tunis, Tunisia
}

\section{Dear Editor,}

With interest we read the article by Berio et al. about a 13-yearold male with Kearns-Sayre syndrome (KSS), manifesting with cardinal features (progressive external ophthalmoplegia, onset $<20 y$, pigmentary retinopathy), and less infrequent, additional features (hypoacusis, ataxia, PNS involvement, short stature, growth hormone deficiency, lactic acidosis, facial dysmorphism, hypoparathyroidism, emesis, aortic insufficiency, subaortic septum hypertrophy, right bundle-branch block, double vision, and white matter lesions). ${ }^{1}$ We have the following comments and concerns.

We do not agree with the statement that cerebral white matter lesions (WMLs) found on imaging are unique to KSS patients. ${ }^{1}$ Patchy or diffuse subcortical WMLs are a frequent finding in mitochondrial disorders (MIDs) with cerebral involvement. Particularly, patients with non-specific mitochondrial syndromes show up with WMLs as described in Berio's case. ${ }^{2}$

The authors hypothesize that WMLs of the described patient were partially due to abnormal representation or migration of neural crest cells. If this is the case, WMLs presented should be present

Correspondence: Josef Finsterer, Krankenanstalt Rudolfstiftung, Messerli Institute, Veterinary University of Vienna, Postfach 20, 1180 Vienna, Austria.

Tel.: +43.1.71165 - Fax: +43.1.4781711.

E-mail: fifigs1@yahoo.de

Key words: Kearns-Sayre syndrome; mtDNA; Leucoencephalopathy; Phenotype; Genotype.

Contributions: JF: design, literature search, discussion, first draft; SZM: literature search, discussion, critical comments.

Conflict of interest: the authors declare no potential conflict of interest. Funding: none.

Note: this Letter to the Editor relates to Berio A, Piazzi A, Traverso CE. Kearns-Sayre syndrome with facial and white matter extensive involvement: a (mitochondrial and nuclear gene related?) neurocristopathy? Pediatr Med Chir 2017;39:107-11.

Received for publication: 19 March 2018.

Accepted for publication: 22 May 2018.

This work is licensed under a Creative Commons Attribution NonCommercial 4.0 License (CC BY-NC 4.0).

CCopyright J. Finsterer and S. Zarrouk-Mahjoub, 2018

Licensee PAGEPress, Italy

La Pediatria Medica e Chirurgica 2018; 40:193

doi:10.4081/pmc.2018.193 already at birth in KSS patients. However, we are not aware of KSS patients with WMLs already at birth.

Since the mother presented with hypothyroidism, a frequent feature of MIDs, we should know if the mother was tested positive for the mtDNA deletion. Though KSS is usually sporadic, in about $4 \%$ of the cases there is transmission via the maternal line. ${ }^{3}$

If cerebral lesions in KSS also occur bilaterally in the substantia nigra, as mentioned in the discussion, we can expect that at least some KSS patients present with Parkinsonism. However, no reports about KSS and Parkinsonism have been published.

With regards to growth retardation, we would be interested to know if there was empty sella, pituitary adenoma, or brainstem lesions.

Overall, this interesting case report requires clarification of some inconsistences and would profit from providing genetic data of first-degree relatives.

\section{References}

1. Berio A, Piazzi A, Traverso CE. Kearns-Sayre syndrome with facial and white matter extensive involvement: a (mitochondrial and nuclear gene related?) neurocristopathy? Pediatr Med Chir 2017;39:107-11.

2. Bindu PS, Sonam K, Chiplunkar S, et al. Mitochondrial leukoencephalopathies: A border zone between acquired and inherited white matter disorders in children? Mult Scler Relat Disord 2018;20:84-92.

3. Poulton J, Finsterer J, Yu-Wai-Man P. Genetic counselling for maternally inherited mitochondrial disorders. Mol Diagn Ther 2017;21:419-29. 